\title{
Females Follow a More "Compact" Early Human Brain Development Model Than Males. A Case-Control Study of Preterm Neonates
}

\author{
GEORGE T. VASILEIADIS, R. TERRY THOMPSON, VICTOR K.M. HAN, AND NEIL GELMAN \\ School of Clinical Sciences [G.T.V.], The University of Nottingham, Nottingham NG7 2UH, United Kingdom; Lawson Health Research \\ Institute [G.T.V., R.T.T., V.K.M.H., N.G.], London, Ontario N6A 4V2, Canada
}

\begin{abstract}
The pattern of sexual differentiation of the human brain is not well understood, particularly at the early stages of development when intense growth and multiple maturational phenomena overlap and interrelate. A case-control study of 20 preterm males and females matched for age was conducted. Threedimensional images were acquired with $3 \mathrm{~T}$ MRI. The cerebral volume and the cortical folding area (FA), defined as the surface area of the interface between cortical gray and white matter, were compared between males and females. Females had smaller cerebra than males even after removing the influence of overall size differences between the subjects. The cortical FA increased in relation to volume by a power of $4 / 3$ in both groups. Females had larger cortical FA compared with males with similar cerebral volumes. The study provides in vivo evidence of sexually dimorphic early human brain development. The relatively more "compact" female model may well relate to sex differences in neural circuitry and cognitive domains. (Pediatr Res 66: 551-554, 2009)
\end{abstract}

$\mathrm{O}$ ver the last decades, there is emerging evidence of early sexual dimorphism of the brain. Studies in animals have shown that fetal testes secrete testosterone independently of gonadotrophins and the male brain is exposed to high levels of these hormones $(1,2)$. Aromatase, the enzyme converting testosterone to estradiol, plays a crucial role in sexually dimorphic prenatal brain development (3-5), and there are malefemale differences in estrogen receptors during fetal development (6-8). Furthermore, genetic studies have reported that the genes associated with sex chromosomes directly affect brain sexual differentiation, suggesting that genetic influence on early brain development precedes or overlaps with the epigenetic action of gonadal hormones (9-12). In humans, MRI can be used to in vivo investigate early morphologic and structural differences between males and females in the developing brain.

Based on the literature, it is evident that hormonal effects and genetic mechanisms influence sex-related brain developmental phenomena. However, the pattern of early sexual

Received May 21, 2009; accepted July 20, 2009.

Correspondence: George T. Vasileiadis, M.D., M.Sc., School of Clinical Sciences, Division of Human Development, The University of Nottingham, Queen's Medical Centre, Nottingham NG7 2UH; e-mail: georgios.vasileiadis@nottingham.ac.uk, gvasilei@lawsonimaging.ca

Supported by the Canadian Foundation for Innovation, the Ontario Innovation Trust, the Ontario Research and Development Challenge Fund, and the Canadian Natural Sciences and Engineering. differentiation of the human brain has not been explored and is not fully understood. It is not clear whether and how sex-related differences in early brain development are related to growth and maturational phenomena such as somatic growth, cerebral growth, and cortical folding.

This study aimed to investigate the pattern of cerebral growth and cortical folding in infants at a preterm stage of development, comparing the findings between males and females. To remove the influence of age, a significant determinant factor of early brain development $(13,14)$, a casecontrolled study was conducted, matching the infants in the two groups for age.

\section{METHODS}

Study design and participants. Written informed consent was given by the parents and ethics approval was received from the University of Western Ontario Health Sciences Research Ethics Board. Preterm infants with weight appropriate for gestational age (AGA) below $1.5 \mathrm{~kg}$ were included in the study for research purposes (15). Exclusion criteria were congenital infections or malformations, metabolic diseases or hypoglycemia, CNS infections, brain malformations, seizures, hypoxic-ischemic injury, necrotizing enterocolitis, bowel perforation, and recurrent sepsis (defined as $>2$ episodes of positive blood cultures).

All infants enrolled in the study had serial cranial ultrasonography studies. Scans were performed by qualified radiology technicians using an ATL, HDI 3500 scanner (Bothell, USA) with a broadband transducer of 8-5 MHz. Each scan received clinical reading by neuroradiologist and neonatologist. Infants with cystic periventricular leukomalacia, parenchymal involvement of hemorrhage, posthemorrhagic hydrocephalus, and ventriculomegaly (defined as $>4 \mathrm{~mm}$ above 97th centile) (16) were excluded before the MRI, on the basis of ultrasonography findings. Males were matched against females one-to-one, based on the postmenstrual age at MRI scan $( \pm 3 \mathrm{~d})$.

MRI. Infants had the MRI scan using a dedicated neonatal 3 T MRI system (IMRIS Winnipeg, Canada). Sound levels were measured to be less than 85 $\mathrm{dB}$ at the center of the coil. Neonates wore molded earplugs (EarClassic; Aearo, Indianapolis, IN) for further sound attenuation. After feeding, they were transferred to the scanner in a cot and a single dose of chloral hydrate $(50 \mathrm{mg} / \mathrm{kg})$ was administered orally for sedation, before scanning. Threedimensional images of the cerebrum were acquired in $6.5 \mathrm{~min}$ with a center-out acquisition, magnetization-prepared rapid gradient echo sequence, with timing parameters optimized for neonatal brain imaging (17-19). Imaging parameters included intersegment repeat time $5200 \mathrm{~ms}$, inversion time $2250 \mathrm{~ms}$, repeat time $10 \mathrm{~ms}$, echotime $5 \mathrm{~ms}$, image bandwidth $33.3 \mathrm{kHz}$, flip angle 10 degrees, matrix size $120 \times 120 \times 75$, and field of view $=160 \times$ $160 \times 100 \mathrm{~mm}$ giving an isotropic resolution of $1.3 \mathrm{~mm}$.

The image analysis was performed on axial slices using Analyze 4.0 software (Biomedical Imaging Resources, Mayo Foundation, Rochester, MN) by a single blinded analyst. To obtain the cerebral tissue volume (CRB; gray and white matter), the skull, extracerebral cerebrospinal fluid, ventricular

Abbreviations: CRB, cerebral tissue volume; FA, folding area 
cerebrospinal fluid, and the cerebellum were extracted. This segmentation and extraction was based on signal intensity thresholds and was performed automatically. The brainstem was traced below the level of the anteroposterior commissure and was also extracted from the cerebrum. The CRB was calculated from the voxel volume and the number of voxels remaining after the extractions. The borderline between cortical gray matter and white matter was manually traced based on the signal intensity difference between the two tissue types (Image 1). Adding the measurements of all slices, the area between cortical gray matter and white matter was calculated and is been referred to here as the folding area (FA) of the cortex. The intraobserver variability for the FA was tested in 10 repeated measurements of the same scan.

Data analyses and statistics. Statistical analysis was performed with SPSS 15.0 for Windows (SPSS Inc, Chicago, IL). CRBs of males were compared with those of the females with an ANOVA. Potential confounding factorscovariates were tested for significance using regression analyses. They were tested first independently, then using a stepwise regression (20). A $p$ value of 0.2 for entry criteria and of 0.1 for exit was used. The FA, defined here as the surface area of the interface between cortical gray matter and white matter, was used as the relevant index of cortical convolution. Because in any three-dimensional object surface is related to volume (for a sphere $s=a v^{b}, s$ stands for surface area, $v$ for volume, $a$ is a constant, $b$ is $2 / 3$ ) (21), the raw and log-transformed data of FA were evaluated in relation to the raw and log-transformed data of CRB in males and females using linear regression. A test for homogeneity of slopes and intercepts was performed to determine whether the regression lines for males were significantly different from that of the females.

\section{RESULTS}

Ten male and 10 female infants were included in the study. The median gestational age and range at birth was 28.7 wk $(24.6,31.7)$ in males and 28 wk $(24.6,29.3)$ in females. The postnatal clinical course characteristics are presented in Table 1.

The CRB was larger $(p=0.012)$ in males than in females. The infants' weight at scan was a significant covariate for the CRB but the difference between males and females remained significant $(p=0.039)$ after adjusting for weight differences between males and females (Table 2 and Fig. 1). Other parameters such as gestational age at birth, weight at birth, days on ventilation, bronchopulmonary dysplasia, days to full feeds, germinal matrix hemorrhage, although not different between the groups, were also entered in the regression model and tested for possible covariance and no significance was demonstrated (all $p$ values $>0.3$ ). The intraobserver variability (SD-SD) for the FA was $<2.5 \%$.

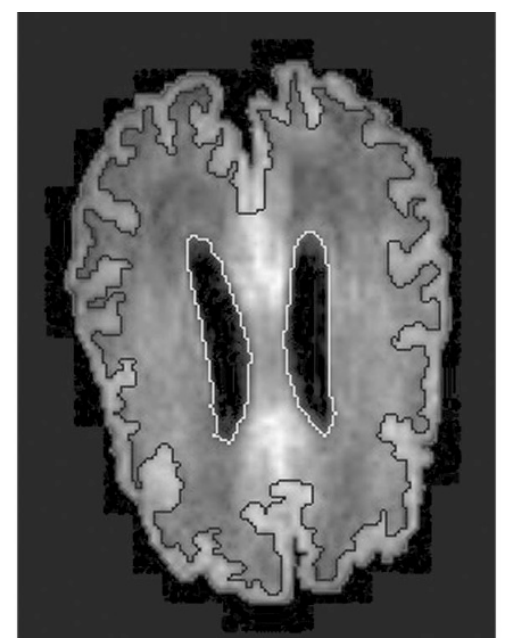

Image 1. Trace of FA.
Table 1. Neonatal clinical data

\begin{tabular}{|c|c|c|c|}
\hline Parameter & $\begin{array}{c}\text { Males } \\
(n=10)\end{array}$ & $\begin{array}{l}\text { Females } \\
(n=10)\end{array}$ & Group difference \\
\hline RDS (infants) & 8 & 7 & $x^{2}=0.27, p=0.61$ \\
\hline $\begin{array}{l}\mathrm{O}_{2} \text { dependency } \\
\text { at } 36 \mathrm{wk} \\
\text { (infants) }\end{array}$ & 5 & 4 & $x^{2}=0.20, p=0.65$ \\
\hline Ventilation $(\mathrm{d})^{*}$ & $35(0,70)$ & $30(0,59)$ & $t$ test, $p=0.39$ \\
\hline $\begin{array}{l}\text { Indomethacin } \\
\text { for PDA }\end{array}$ & 3 & 3 & \\
\hline $\begin{array}{l}\text { Corticosteroids } \\
\quad \text { (infants) }\end{array}$ & 2 & 2 & \\
\hline $\begin{array}{l}\text { Germinal matrix } \\
\text { hemorrhage }\end{array}$ & 3 & 4 & $x^{2}=0.22, p=0.64$ \\
\hline Sepsis (infants) & 5 & 6 & $x^{2}=0.20, p=0.65$ \\
\hline $\begin{array}{l}\text { Breast milk } \\
\quad \text { (infants) }\end{array}$ & 9 & 9 & \\
\hline Full feeds $(\mathrm{d}) *$ & $31.5(12,50)$ & $29.5(16,51)$ & $t$ test, $p=0.74$ \\
\hline $\begin{array}{l}\text { Weight at scan } \\
\qquad(\mathrm{kg}) \dagger\end{array}$ & $2.40 \pm 0.27$ & $2.23 \pm 0.27$ & $t$ test, $p=0.21$ \\
\hline $\begin{array}{l}\text { Age at scan } \\
\text { (wk)* }\end{array}$ & $35.7(34.6,36.9)$ & $35.8(34.3,37.1)$ & $t$ test, $p=0.98$ \\
\hline
\end{tabular}

* Median (range).

$\dagger$ Mean \pm SD.

RDS, respiratory distress syndrome; BPD, bronchopulmonary dysplasia; PMA, postmenstrual age; PDA, persistent ductus arteriosus.

Table 2. Cerebral tissue volume (CRB) data displayed as mean $\pm S D$

\begin{tabular}{ccccccc}
\hline & $\begin{array}{c}\text { Males } \\
(n=10)\end{array}$ & $\begin{array}{c}\text { Females } \\
(n=10)\end{array}$ & $F$ & $p$ & $F^{*}$ & $p^{*}$ \\
\hline CRB $(\mathrm{mL})$ & $271 \pm 17.6$ & $245 \pm 24.1$ & 7.832 & 0.012 & 5.013 & 0.039 \\
\hline
\end{tabular}

" $F$ " value reported is the $F$-statistic.

* Values adjusted for infants' weight at MRI scan.

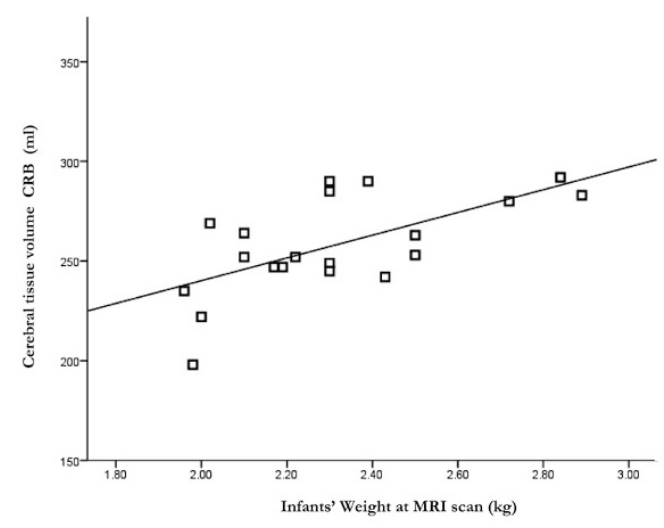

Figure 1. Scatterplot for CRB with weight at MRI scan $\left(R^{2}=0.39\right)$.

The relationship of the cortical FA with the cerebral tissue for males and females is shown in Figure 2. The differences between the slopes were not significant $(p=0.95 ; F<0.01$; pooled slope $=2.66$ ). However, the intercepts were significantly different $(p=0.019 ; F=6.78)$. The relationship between the log-transformed data of the FA and the CRB is shown in Figure 3. The differences between the slopes were not significant $(p=0.87 ; F<0.05$; pooled slope $=1.35$ ). However, the intercepts were significantly different $(p=$ $0.018 ; F=6.80$ ). 


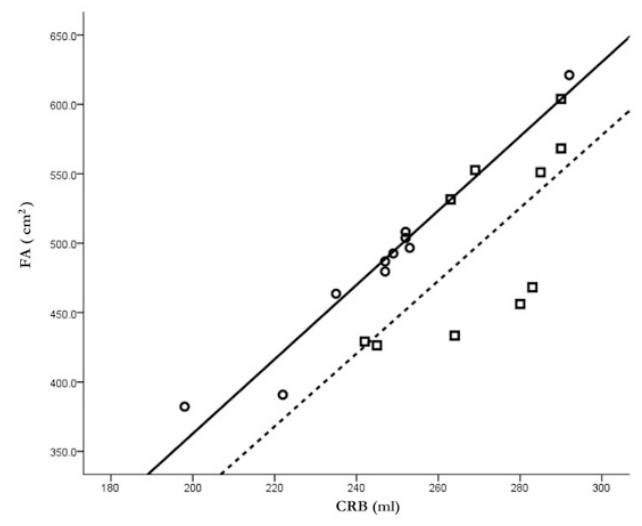

Figure 2. Scatterplot and best-fit line for CRB and FA. Males ( $\square$ ): FA = $2.62 \times \mathrm{CRB}-209.1, R^{2}=0.48$; Females $(\bigcirc): \mathrm{FA}=2.68 \times \mathrm{CRB}-172.7$, $R^{2}=0.95$.

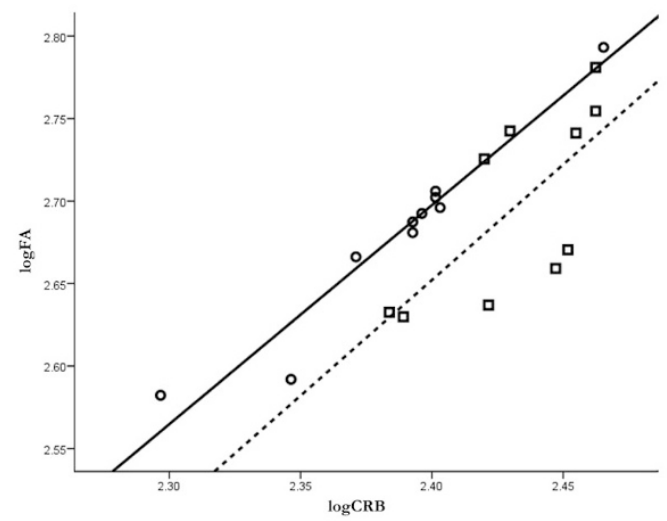

Figure 3. Scatterplot and best-fit line for $\log \mathrm{CRB}$ and $\log \mathrm{FA}$. Males ( $\square$ ): $\mathrm{FA}=1.40 \times \mathrm{CRB}-0.71, R^{2}=0.49 ;$ Females $(\bigcirc)$ FA $=1.33 \times \mathrm{CRB}-$ $0.49, R^{2}=0.94$.

\section{DISCUSSION}

Previous studies in humans have also shown that the cerebrum is larger in males than in females. This difference is present in adults $(22,23)$, in children $(24,25)$, and in infants (26). In preterm neonates, at an earlier stage of life than this study, it has been observed that males have larger cerebrum than females, and females have a higher sulcation index than males only after adjusting for total brain volume/surface (27). This study investigated these brain developmental aspects taking into account the somatic growth differences in males and females, and also explored the direct relationship of cerebral volume with cortical FA measurements in males and females at near term age. It is important to note that the male and female infants in our study had similar antenatal and postnatal characteristics and no major brain injury. In addition, by matching the male and female subjects according to age, the influence of the very active growth and maturation that occurs at this stage was removed, creating a homogenous cohort. However, the possibility of subtle or diffuse white matter injury cannot be excluded. Brain development involves growth and maturation phenomena, which are strongly linked and intertwined. At a preterm stage, these phenomena are highly active and complicated. It is interesting but not surprising at this age that the weight, which is an indicator of the overall somatic growth, was found to account significantly for variation in cerebral growth. However, the difference in cerebral growth between males and females persisted after adjusting for the influence of this parameter, indicating that sexual dimorphism is an independent determinant of brain development in early human life.

During phylogeny and brain ontogeny, the convoluted external cortical surface area follows a power law that approximately lies between $8 / 9$ and $4 / 3(28,29)$. This study showed that the cortical FA-interface between cortical gray matter and white matter-increases in relation to CRB by a power of $4 / 3$ (if $\log$-transform the data: $\log s=b \log v+\log a$, then the $b$ value is the slope: $1.35 \approx 4 / 3$ ), a value that was not dissimilar between males and females. Strikingly, the regression line plotted significantly higher in females than males meaning that for similar CRBs the corresponding cortical FA was larger in females. These findings of females having smaller CRB than males but having disproportionately larger cortical FA, present a sexually dimorphic brain development with a relatively more "compact" female brain. The "compact" female model is further supported by the stronger correlation between CRB and cortical FA in females than in males.

The more "compact," compared with males, early female brain development model is an interesting finding on brain macrostructure and refers potentially to underlying sexual differences in brain microstructure. The sexual differentiation of the developing brain in oligodendrocytes, astrocytes, and related processes or mechanisms is evident in the rodent brain and highly possible in humans (30-32). Considering the tension-based theory of brain morphogenesis, these microstructural phenomena and differences between males and females can lead to differences in tension along axons and tissue anisotropy which in turn may well result in different cortical FA and pattern in males and females, as found in this study $(33,34)$. Furthermore, the more "compact" female brain development model can be associated with lower aggregate length of axonal and dendritic wiring and compactness of neural connectivity and circuitry. This may contribute to differences in domains of cognitive function and developmental performance early or later in life, underlining sex as an independent influencing factor $(35,36)$.

The highly complex process of brain development is especially challenging to investigate during this dynamic phase of fetal or early life period. The very active growth of cerebral tissue, combined with essential multiple tissue organization phenomena, continues to raise fundamental questions. This study provides novel macroscopic in vivo evidence of a sexually dimorphic brain developmental model at an early stage of human life. Females have smaller CRBs independently to overall size, but disproportionately larger cortical FA than males following a more "compact" brain developmental model. Longitudinal studies in humans shall provide more insight into the pattern of sexual brain dimorphism and how this evolves.

Acknowledgment. We thank Rupinder Man for her meticulous work on image analysis. 


\section{REFERENCES}

1. Picon R 1976 Testosterone secretion by foetal rat testes in vitro. J Endocrinol 71:231-238

2. Weisz J, Ward IL 1980 Plasma testosterone and progesterone titers of pregnant rats, their male and female fetuses, and neonatal offspring. Endocrinology 106:306-316

3. Beyer C, Green SJ, Barker PJ, Huskisson NS, Hutchison JB 1994 Aromataseimmunoreactivity is localised specifically in neurones in the developing mouse hypothalamus and cortex. Brain Res 638:203-210

4. Hutchison JB 1997 Gender-specific steroid metabolism in neural differentiation. Cell Mol Neurobiol 17:603-626

5. Quadros PS, Pfau JL, Goldstein AY, De Vries GJ, Wagner CK 2002 Sex differences in progesterone receptor expression: a potential mechanism for estradiol-mediated sexual differentiation. Endocrinology 143:3727-3739

6. Clark AS, MacLusky NJ, Goldman-Rakic PS 1988 Androgen binding and metabolism in the cerebral cortex of the developing rhesus monkey. Endocrinology 123:932-940

7. Michael RP, Zumpe D, Bonsall RW 1992 The interaction of testosterone with the brain of the orchidectomized primate fetus. Brain Res 570:68-74

8. Sholl SA, Kim KL 1989 Estrogen receptors in the rhesus monkey brain during fetal development. Brain Res Dev Brain Res 50:189-196

9. Lahr G, Maxson SC, Mayer A, Just W, Pilgrim C, Reisert I 1995 Transcription of the $\mathrm{Y}$ chromosomal gene, Sry, in adult mouse brain. Brain Res Mol Brain Res 33:179-182

10. Mayer A, Lahr G, Swaab DF, Pilgrim C, Reisert I 1998 The Y-chromosomal genes SRY and ZFY are transcribed in adult human brain. Neurogenetics 1:281-288

11. Xu J, Burgoyne PS, Arnold AP 2002 Sex differences in sex chromosome gene expression in mouse brain. Hum Mol Genet 11:1409-1419

12. Carruth LL, Reisert I, Arnold AP 2002 Sex chromosome genes directly affect brain sexual differentiation. Nat Neurosci 5:933-934

13. Huppi PS, Warfield S, Kikinis R, Barnes PD, Zientara GP, Jolesz FA, Tsuji MK, Volpe JJ 1998 Quantitative magnetic resonance imaging of brain development in premature and mature newborns. Ann Neurol 43:224-235

14. Ajayi-Obe M, Saeed N, Cowan FM, Rutherford MA, Edwards AD 2000 Reduced development of cerebral cortex in extremely preterm infants. Lancet 356:1162-1163

15. Gairdner D, Pearson J 1988 Growth Chart for Premature and Other Infants Castlemead Publications, Hertfordshire, UK

16. Levene MI 1981 Measurement of the growth of the lateral ventricles in preterm infants with real-time ultrasound. Arch Dis Child 56:900-904

17. Mugler JP III, Brookeman JR 1990 Three-dimensional magnetization-prepared rapid gradient-echo imaging (3D MP RAGE). Magn Reson Med 15:152-157

18. Deichmann R, Good CD, Josephs O, Ashburner J, Turner R 2000 Optimization of 3D MP-RAGE sequences for structural brain imaging. Neuroimage 12:112-127

19. Williams LA, DeVito TJ, Winter JD, Orr TN, Thompson RT, Gelman N 2007 Optimization of 3D MP-RAGE for neonatal brain imaging at 3.0 T. Magn Reson Imaging 25:1162-1170
20. Vasileiadis GT 2007 Neonatal brain volumetric studies: regression analysis and interpretation. Pediatrics 119:1251-1252

21. Netz R 2004. The Works of Archimedis: On the Sphere and the Cylinder. Cambridge University Press, Cambridge, UK

22. Gur RC, Turetsky BI, Matsui M, Yan M, Bilker W, Hughett P, Gur RE 1999 Sex differences in brain gray and white matter in healthy young adults: correlations with cognitive performance. J Neurosci 19:4065-4072

23. Goldstein JM, Seidman LJ, Horton NJ, Makris N, Kennedy DN, Caviness VS Jr, Faraone SV, Tsuang MT 2001 Normal sexual dimorphism of the adult human brain assessed by in vivo magnetic resonance imaging. Cereb Cortex 11:490-497

24. Reiss AL, Abrams MT, Singer HS, Ross JL, Denckla MB 1996 Brain development, gender and IQ in children. A volumetric imaging study. Brain 119:1763-1774

25. Reiss AL, Kesler SR, Vohr B, Duncan CC, Katz KH, Pajot S, Schneider KC, Makuch RW, Ment LR 2004 Sex differences in cerebral volumes of 8-year-olds born preterm. J Pediatr 145:242-249

26. Gilmore JH, Lin W, Prastawa MW, Looney CB, Vetsa YS, Knickmeyer RC, Evans DD, Smith JK, Hamer RM, Lieberman JA, Gerig G 2007 Regional gray matter growth, sexual dimorphism, and cerebral asymmetry in the neonatal brain. J Neurosci 27:1255-1260

27. Dubois J, Benders M, Cachia A, Lazeyras F, Ha-Vinh Leuchter R, Sizonenko SV, Borradori-Tolsa C, Mangin JF, Hüppi PS 2008 Mapping the early cortical folding process in the preterm newborn brain. Cereb Cortex 18:1444-1454

28. Prothero J 1997 Cortical scaling in mammals: a repeating units model. J Hirnforsch 38:195-207

29. Zhang K, Sejnowski TJ 2000 A universal scaling law between gray matter and white matter of cerebral cortex. Proc Natl Acad Sci USA 97:5621-5626

30. Marin-Husstege M, Muggironi M, Raban D, Skoff RP, Casaccia-Bonnefil P 2004 Oligodendrocyte progenitor proliferation and maturation is differentially regulated by male and female sex steroid hormones. Dev Neurosci 26:245-254

31. Cerghet M, Skoff RP, Bessert D, Zhang Z, Mullins C, Ghandour MS 2006 Proliferation and death of oligodendrocytes and myelin proteins are differentially regulated in male and female rodents. J Neurosci 26:1439-1447

32. Schwarz JM, McCarthy MM 2008 Cellular mechanisms of estradiol-mediated masculinization of the brain. J Steroid Biochem Mol Biol 109:300-306

33. Thompson D 1917 On Growth and Form. Cambridge University Press Cam bridge, UK

34. Van Essen DC 1997 A tension-based theory of morphogenesis and compact wiring in the central nervous system. Nature 385:313-318

35. Rutter M, Caspi A, Fergusson D, Horwood LJ, Goodman R, Maughan B, Moffitt TE, Meltzer H, Carroll J 2004 Sex differences in developmental reading disability: new findings from 4 epidemiological studies. JAMA 291:2007-2012

36. Hintz SR, Kendrick DE, Vohr BR, Kenneth Poole W, Higgins RD; for The Nichd Neonatal Research Network 2006 Gender differences in neurodevelopmental outcomes among extremely preterm, extremely-low-birthweight infants. Acta Paediatrica 95:1239-1248 